\title{
Development of a Physical Activity Program for Delinquent Out-of-School-Youth: Intervention for Violence
}

\author{
Leonard Sydrick H. Pajo \\ Physical Education Instructor \\ Davao Oriental State College of Science and Technology \\ Corazon T. Biong \\ Professor, MSU-lligan Institute of Technology \\ corazonbiong05@yahoo.com
}

\section{Doi:10.5901/mjss.2013.v4n9p566}

Abstract

This study aimed mainly at developing the first ever research-based anti youth violence program in Mati City, specifically designed for the target out-of-school-youth group. The descriptive-correlational method of study was utilized to explore the possibilities of having physical activity as an intervention for violence among out-of-school-youth. Data were gathered from 35 out-of-school-youth of Barangay Central, Mati City Davao Oriental, aging from 13-21 years old and who have already incurred a criminal record. The results of this study showed that almost half of the youth with criminal records are minors. The respondents manifested that basketball is the most popular Physical Activity followed by card games and hip hop dance. It is worth taking note of that all dance activities are participated. Furthermore, results revealed that Team sports, have a potential negative correlation to violence which means as the activity increases, violence decreases. Physical activities that will potentially reduce physical aggression are the following: Basketball ( $r=-0.037$; volleyball $(r=-0.021)$; Cheerdance $(r=-0.093)$; and card games (r=-0.006). Individual sports participation showed the highest effect on violence, followed by the socio economic status. Hence, it was highly recommended that the developed program be anchored on physical activities with negative correlation towards violence such as basketball, hip-hop, and cheer dance, and that the developed program is implemented.

Keywords: youth, violence, sports, physical activities

\section{Introduction}

Violence is an everyday act committed by billions of people around the world. Everyone has been affected by violence and many people have committed violent acts or crimes (Leone, Meyer, Malgren, \& Misel, 2000). Focusing on violence in today's society and its causes, one might ask who is to be blamed. It may be human nature on his psychological and physiological characteristics. According to Perry (2000) everyone is born with violent personality inside, so it is a natural instinct for him to be aggressive; what turns aggression into violence is the secondary root; the nurture that a person receives. Based on the conducted survey of Farrington (1998), a persons' physiology is an important factor towards violence because it establishes how hostile a person will be. Just like anywhere else, Mati city (the area of study) is a place also greatly affected by youth violence. Most of these are carried out by youth gangs and out of school youths usually coming from the city's most populated barangay-- Barangay Central. Series of gang wars, vandalism, destruction of public and private properties, are among the many crimes that concern these delinquents and these cause detrimental effects on the society to which they belong. Today, the City of Mati has been enthusiastically implementing many attempts to reach out to the youth and combat their violence. But unfortunately these efforts of change have been more futile rather than beneficiary. This may be due to the reason that these approaches have been less scientific and unspecific. Nevertheless, it is still worth exploring to look for more ways and means to finally lessen or probably eradicate the problem that is violence.

This paper seeks to develop a more scientific approach with the use physical activities as an intervention for violence among the out of school youth of Barangay Central, Mati City. This study intends to realize the following objectives: (1) to provide the first research-based youth violence intervention program specific for the delinquent Out-ofSchool-Youth of Barangay Central, Mati City, Davao Oriental; (2) to determine the crime in Barangay Central, Mati City, 
Davao Oriental; (3) to ascertain what sport could gauge violent tendencies; and (4) to establish if there is a relationship between Physical Activity Participation and Violence.

In this inquiry, the researchers were determined to answer the following questions: (1) what is the profile of the respondents in terms of their age, socio economic status, violence susceptibility, physical activity participation, violence, aggression, alcoholic exposure, and crime rate. (2) Is there a significant relationship between the Physical activity participation and violence among the male out-of-school-youth of Mati City, Davao Oriental? (3) How does aggression, socio-economic status, alcoholic exposure, and violence susceptibility, interplay in the relationship between physical activity participation and violence? (4) What physical activity program can be developed based on the results of the study?

\section{Literature Review}

Svoboda (1994) offered a similar study, for him participation provides an opportunity to meet and communicate with other people, take different social roles, learn particular social skills (tolerance; respect for others); and to adjust to team/collective objectives (co-operation, cohesion). He further stated that it contributes to personality development; provides experience of emotions which are not available in the rest of life and improves aspects of lifestyle. Svoboda (1994) stresses the important contribution of sport to processes of personality development and psychological well-being. Moreover he stressed that there is "strong evidence ... on the positive effects of physical activities on self-concept, selfesteem, anxiety, depression, tension and stress, self- confidence, energy, mood, efficiency and well-being". Wankel and Sefton (1994) listed the social and psychological benefits of sport and physical activity as reduction of anxiety and depression, socialization, intergroup relations, community integration, educational attainment, social status and social mobility. This also emphasizes the cathartic role of physical activities in providing an opportunity to an institutionalized display of force, strength and competitiveness and the opportunity for the display of adolescent masculinity. Sport is viewed as providing an opportunity to address the needs of adolescents to develop perceptions of efficacy, competence, control, freedom and independence (Maughan \& Ellis, 1991; Hendry et al, 1993).

There are three major theories that seek to explain violent aggression in sports (Terry \& Jackson, 1985; Leonard, 1988). The biological theory, proposed most notably by Nobel prize winner Konrad Lorenz, sees aggression as a basic, inherent human characteristic. Within this context, sports are seen as a socially acceptable way to discharge built-up aggression, a safety valve. On the other hand, the psychological theory states that aggression is caused by frustration; it is situational. Frustration results when one's efforts to reach a particular goal are blocked (Leonard, 1988). In sports, frustration can be caused by questionable calls by officials, failure to make a particular play, injuries that interfere with optimum performance, heckling from spectators, or taunts by coaches or players. Moreover, the social learning theory has received the most empirical verification, Leonard (1988) maintains that aggressive behavior is learned through modeling and reinforced by rewards and punishments. Young athletes take sports heroes as role models and imitate their behavior. Parents, coaches and teammates are also models who may demonstrate support for an aggressive style of play.

\section{Conceptual Framework}

The research paradigm summarizes the relationship between the Independent Variable which is Physical activity participation, the dependent variable which is violence and the moderating variables which are aggression, socioeconomic status, alcoholic exposure, and violence susceptibility. It can also be seen that as a result of this process, a physical activity program will be made as an output based on the obtained results. 
Independent Variable

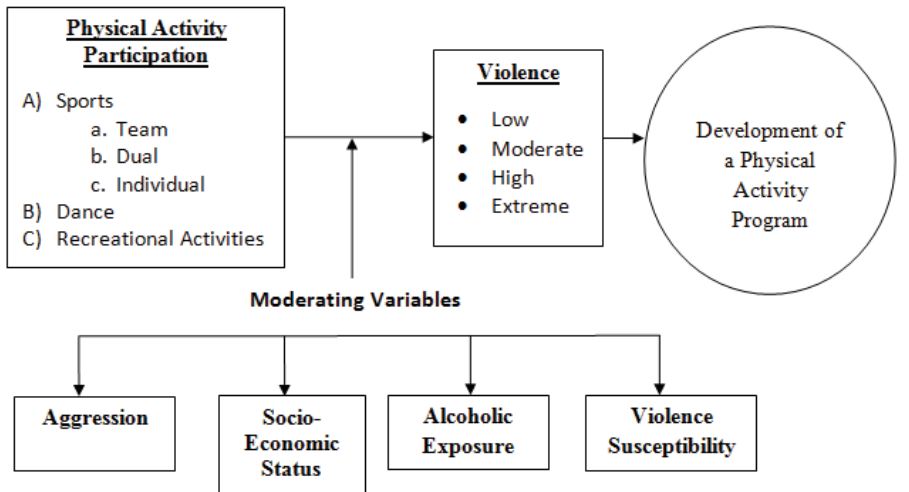

\section{Methodology}

\subsection{Research Design}

The study employed the descriptive-correlational research method. This design enabled the researcher to systematically describe the nature of the situation as it exists at the time of the study and explore the cause of a particular phenomenon. This method is also used because there were a relatively large number of subjects and the researcher can only afford few respondents. It only measured existing phenomenon without inquiring why it exist.

\subsection{Research Locale}

This research was conducted at Mati city. As the capital city of the Province of Davao Oriental which belongs to the vast Davao region, this is located in the southern part of Mindanao. The City is noted to have a number of juvenile delinquent incidents that included substance abuse, theft, violent gang wars and even homicide. At present, a new breed of young delinquents are increasing most especially in highly congested barangays within the city limit, one of which is Barangay Central. This barangay is the target area of this study.

\subsection{Respondents of the Study}

The respondents of the study were the delinquent male Out-of-School-Youth who are residents of Barangay Central, Mati City with ages ranging from 13-21 yrs. old. The youth living in this area are noted to be more violent as compared to other youth of other barangays. All of the respondents were being identified by looking through police criminal records and files.

\subsection{Instrument of the Study}

The research used a self-made questionnaire, validated by the research adviser, at the same time also employed related standardized test to ensure proper assessment of the involved variables such as violence-Youth Violence Screening Questionnaire (Cooke, Michie, \& Ryan ,2001), aggression-Aggression Questionnaire (Buss \& Perry, 1992), violence susceptibility-Childhood and Adolescent Taxon Scale and Violence Risk Appraisal Guide (Boer, Wilson, Gauthier \& Hart, 1997).

\subsubsection{Self-Made Instrument}

The self-made instrument was subdivided into different profiles of the respondents like physical activity in terms of sports which is composed of team and individual/dual sports, dance and recreational activities. Each of these variables was gauged according to frequency/week (once=1 point, twice $=2$ points, and thrice or more $=3$ points) and intensity (high= 3 
points, medium $=2$ points, low=1 point). Points obtained from the frequency and intensity of participation were added and the sum was divided by two to get the average level of participation. After which, the average score was then categorized into three levels of participation which are: Low (0 to 1 point), Moderate (1.1 to 2 points) and High (2.1 to 3 points). The moderating variables were another part of the questionnaire that included the socio-economic status with five categories of their parents' annual income which are: Very poor- <20,000 Php/year; Poor- 21,000 Php to 100,000 Php/year; Average- 101,000 Php to 200,000 php/year; Rich- 200,000 Php to 400,000 Php/ year; Very Rich- >401,000 Php., and alcoholic exposure which involves the categories such as: always-6 or more times a week, often- $4-5$ times a week, seldom 2-3 times a week, rarely once a week, and never.

\subsubsection{Youth Violence Screening Questionnaire}

The Youth Violence Screening Questionnaire was a 50 item standardized test used to measure youth violence. Each item was scored differently based on the intensity of each items content, in which items 1 to 17 were scored as one point each, items 18 to 36 were scored as five points each, items 37 to 41 were scored as ten points each, items 42 to 46 were scored as fifteen points each, and items 47 to 50 were scored as twenty points each. Each item was a description of a violent behavior and if the description fits the respondents' personality, then it will be checked. The total score was determined by adding up all the scores obtained from each checked item. The total score was then categorized as Lowly violent (if total score ranges from 5 to 16 points), Moderately violent (if total score ranges from 17to 32 points), Highly violent (if total score ranges from 33 to 84 points), and Extremely violent (if total score ranges from 85 points or more).

\subsubsection{Aggression Questionnaire}

The aggression questionnaire was a standardized test that was divided into two forms of Aggression which are Physical aggression and Verbal aggression. Both Physical and Verbal aggression have seven items each. Each item was rated as "extremely uncharacteristic of me" which was equivalent to one point, "somewhat uncharacteristic of me" which was equivalent to two points, "neither uncharacteristic nor characteristic of me" which was equivalent to three points, "somewhat characteristic of me" which was equivalent to four points, and "extremely characteristic of me" which was equivalent to five points. Scores obtained were totalled separately according to each aggression type. Items 1, 3, 7, 9, 11, 12, and 14 were for Physical Aggression, and items 2, 4, 5, 6, 8, 10, and 13 were for Verbal Aggression. After which, the total score for each type was categorized as Very Low (7-13 points), Low (14-20 points), Moderate (21-27), and High (28-35).

\subsubsection{Cormier-Lang System}

The Cormier-Lang System of Criminal History scoring was a test used only for item number 11 of the Violence Risk Appraisal Guide (VRAG). Criminal History score was obtained by multiplying the number of times the offense was committed to the points assigned for each different type of offense. The products for each offense were added and the sum was the total score.

\subsubsection{Childhood and Adolescent Taxon Scale (CATS) and the Violence Risk Appraisal Guide (VRAG)}

The Childhood and Adolescent Taxon Scale (CATS) and the Violence Risk Appraisal Guide (VRAG) was a combined test series used to determine violence risk or susceptibility. Each item of the test has different points for different choices under it. The scores of the 15 items were added and these made as the over-all score for both tests which then made as the over-all score for the whole test series. The overall score is categorized as low if it ranges from -15 to -4 , moderate if it ranges from -3 to 11 and high if it ranges from 12 to $25+$. The entirety of the questionnaire was pre-tested to some outof-school-youth outside Barangay Central in order to ensure that this was understood by the respondents and that ambiguous items be edited and clarified.

\subsection{Sampling Technique}

In obtaining the sample needed for the conduct of this study, purposive sampling was utilized. This was done by getting the names of the delinquent male OSY who have criminal backgrounds at the police records. It was found that there 
were only 35 OSY recorded. So the researcher decided to have a complete enumeration of these OSY's with police record.

\subsection{Data Gathering}

The researcher first asked permission from the Barangay Captain of the target barangay. Upon given the permission, the researcher then retrieved data and information of reported out-of-school-youth with delinquent records from the Barangay Office, Police Station, and the Department of Social Welfare and Development (DSWD). With these, the researcher found it easier to locate and interview the respondents. A one-on-one interview was done in order to combat the illiteracy factor and ensure full comprehension on every item. During the interview, a range of instruments both self-made and standardized test and questionnaires were used. After which, raw data gathered from the interview were submitted to the statistician for analysis and interpretation.

\subsection{Statistical Treatment}

This research used both descriptive and parametric statistical analysis. Descriptive analysis was employed for the personal profile of the respondents like frequency distribution, and percentages. Meanwhile, parametric analysis was used to test the given hypotheses. Parametric analysis specifically the Pearson $r$, was used to measure the relationship among the variables. In measuring the interplay of moderating variables the regression analysis was used. Here, it was determined which variable gave the biggest amount of contribution towards violent behavior among the OSY.

\section{Results and Discussion}

This study sought to draw the profile of 35 out-of-school-youth of Barangay Central, Mati City with criminal records which are mainly composed of age, socio-economic status, physical activity participation, violence, alcoholic exposure, aggression, and violence susceptibility. It found out that there was a relationship between physical activity participation and violence. The study as result also found out the aggregate relationship of physical activity, violence, aggression, and violence susceptibility. Lastly, the study pointed the interplay between the moderating variables socio-economic status, alcoholic exposure, aggression and susceptibility with violence.

The respondents' profile was analyzed descriptively using frequency counts and percentages, while the relationships and moderating variable interplay were analyzed parametrically using Pearson $r$ and regression analysis respectively. Findings showed that almost half of the respondents with criminal records were minors (45.7\%). All came from either poor $(74.3 \%)$ or very poor $(25.7 \%)$ family background.

In terms of the most popular physical activity among the respondents, it was noticed that basketball was with 2.55 level of participation (0-3; average level of participation), while baseball, sepak takraw, tennis, larong lahi and mind games were physical activities with no participation. Results also showed that all dance activities were participated.

Furthermore, as regards to violence susceptibility the respondents manifested that their vulnerability were ranging from extremely violent (89\%), highly violent (8\%), and moderately violent (3\%). They have physical aggression (51\%), and both moderate (37\%) and high (37\%) verbal aggression. They had always been exposed to alcohol (37\%) but (20\%) of them never had any exposure to alcoholic drinks. All of them had violence susceptibility; $51 \%$ high and $49 \%$ moderate. Findings showed positive relationship between violence and individual which means that individual sports promote violence.

In the aspect of team sports specifically basketball can suppress violence since this sport has inverse relationship with violence $(r=-0.076)$. Again individual sports led in enhancing physical aggression with table tennis $r=0.307$ and martial arts $r=0.304$, whereas basketball $(r=-0.037)$, volleyball $(r=-0.02)$; cheer dance $(r=-0.093)$ and card games $(r=-$ 0.006 can potentially reduce physical aggression. Verbal aggression almost had the same result with physical aggression. Individual sports again lead in promoting verbal aggression with table tennis $(r=0.3)$, martial arts, boxing, and badminton, while basketball ( $r=-0.174)$, hip-hop ( $r=-0.098)$, cheer dance $(r=-0.052)$ and card games $(r=-0.099)$ potentially reduced verbal aggression. Meanwhile, the relationship between physical activity and violence susceptibility showed basketball $(r=-0.210)$ and volleyball $(r=-0.100$ to potentially lessen violence susceptibility.

Table 1 shows the result of the aggregate relationship of physical activity and violence, aggression and violence susceptibility found individual sports to have a direct relationship with violent behavior of respondents $(r=0.351)$. Team sports on the other hand had inverse relationship with violence susceptibility. 
Table 1. Pearson correlation matrix between aggregate physical activity, violence, aggression and violence susceptibility

\begin{tabular}{|l|c|c|c|c|}
\hline Physical Activity & Violence & $\begin{array}{c}\text { Physical } \\
\text { Aggression }\end{array}$ & $\begin{array}{c}\text { Verbal } \\
\text { Aggression }\end{array}$ & $\begin{array}{c}\text { Violence } \\
\text { Susceptibility }\end{array}$ \\
\hline Team Sports & 0.056 & 0.123 & 0.022 & -0.178 \\
\hline Individual Sports & 0.351 & 0.299 & 0.276 & 0.082 \\
\hline Dance & 0.039 & 0.016 & -0.061 & 0.131 \\
\hline Recreational Activities & 0.125 & -0.006 & -0.099 & 0.210 \\
\hline
\end{tabular}

The interplay with violence and moderating variables together with individual sports showed good fit $(R=0.813)$ and coefficient of determination $\left(\mathrm{R}^{2}=0.6609\right)$. This means that $66.09 \%$ of the violent behavior of the respondents can be explained by the independent variable as well as the moderating variables. Results further showed that individual sports participation have the highest effect on violence with regression coefficient of 5.239. This was followed by the socioeconomic status while alcohol exposure has the least effect on violence.

\section{Findings}

Based on the results of this study the researchers found that:

1. Poverty could be one of the main causes why youth have already committed crime at an early age;

2. Most youth who become violent begin during their adolescent stage;

3. All respondents were susceptible to violence and they are violent at different levels;

4. $66.09 \%$ of the violent behavior of the respondents can be explained by the independent variable and moderating variables;

5. Majority of the respondents have high physical aggression and verbal aggression ranging from moderate to high;

6. Majority of the respondents indulge in alcoholic drinks;

7. Basketball is the most participated physical activities among young people;

8. Baseball, sepak takraw, tennis, larong lahi and mind games were physical activities with no participation;

9. The theory negative association with physical activity is proven true for basketball, volleyball as well as dancing.

10. All dance activities are participated in by the respondents;

11. Team sports have potential negative correlation with violence and physical aggression;

12. Individual sports have a positive relationship with violence, physical aggression, verbal aggression, and violence susceptibility;

\section{Conclusion}

In the real world young people at adolescent stage needs exceptional attention and proper guidance from parents so that they will be able to attain good future. Supervision is a requirement in order for the youth to manage incomparable behavior in the society. They should be exposed to physical activities that in one way or another would lead them to become a commendable members of the community. Involvement or participation in sports and other productive activity should be encouraged in order that they will not become susceptible to illegal activities.

\section{Recommendations}

In the light of the findings and conclusion of this study the researchers drawn the following recommendations: Intensified sports clinic should be given to the OSY's of the identified sports with negative relationships to violence like basketball, volleyball, and dancing;

1. Although results showed that individual sports have been found out to be negatively correlated with violence, further study should be conducted to test and verify this finding.

2. This study should be replicated with a bigger scope and with the inclusion of delinquent female OSY to obtain more reliable data related to the variables being studied.

3. A study should be conducted which will include youth without police records to find out if the violent tendency is present; 
4. Future researchers should seek to employ more variables such as drug abuse and other psycho-social factors and causes of violence in order to further determine and diagnose specific activities that could potentially combat violence among youth.

\section{References}

Boer, D. P, Wilson, R. J., Gauthier, C. M. \& Hart, S.(1997a) The childhood and adolescent taxon scale(cats). retrieved: 2008. from www.tennessee.gov/mental/policy/MHDD vrag.pdf

Boer, D. P, Wilson, R. J., Gauthier, C. M. \& Hart, S.(1997b) The violence risk appraisal guide (vrag). retrieved :2008. www.tennessee.gov/mental/policy/ MHDDvrag.pdf

Buss, A.H., \& Perry, M. (1992). The aggression questionnaire. www.psychology.iastate.edu. retrieved: 2008. Error! Hyperlink reference not valid./faculty/caa/Scales/BussPerry.pdf

Cooke, D. J., Michie, C. \& Ryan, J. (2001) Youth violence screening questionnaire . retrieved: 2008. Error! Hyperlink reference not valid. YouthViolence Screen

Cormier, C \& Lang, C (1998).Cormier - lang criminal history scores. retrieved:2008. www.tennessee.gov/mental/ policy/MHDDvrag. pdf

Farrington (1998) Predictors, causes, and correlates of male youth violence (from youth violence). retrieved: 2009. Error! Hyperlink reference not valid.

Hendry, L.B., Shucksmith, J., Love, J.G. \& Glendinning, A. (1993) Young people's leisure and lifestyles, London, Routledge

Leonard, W M. (1988) A sociological perspective of sport (Third Edition). New York, Macmillan Publishing Company

Leone, P.E., Mayer, M. J., Malmgren, K., \& Misel, S.M. (2000). School violence and disruption: rhetoric, reality, and reasonable balance. Focus on Exceptional Children, 33, 1-20.

Maugham, M. \& Ellis, G.D. (1991) Effect of efficacy information during recreationparticipation on efficacy judgements of depressed adolescents, Therapeutic Recreation Journal, 25(1), pp.50-59

Perry, B. (2000). Aggression and violence the neurobiology experience. Retrieved: 2009.http:// teacher. scholastic .com/ professional/ bruceperry /aggression_violence.htm

Svoboda, B. (1994). Sport and physical activity as a socialization environment: Scientific review part 1, Council of Europe, Committee for the Development of Sport (CDDS)

Terry, Peter C. \& Jackson, John J. (1985). The determinants and control of violence in sport. Quest, 37 (1) 27-37.

Wankel, L.M. and Sefton, J.M. (1994). Physical activity, fitness and health, (pp.530-554),Champaign, IL, Human Kinetics Publishers, Inc. 